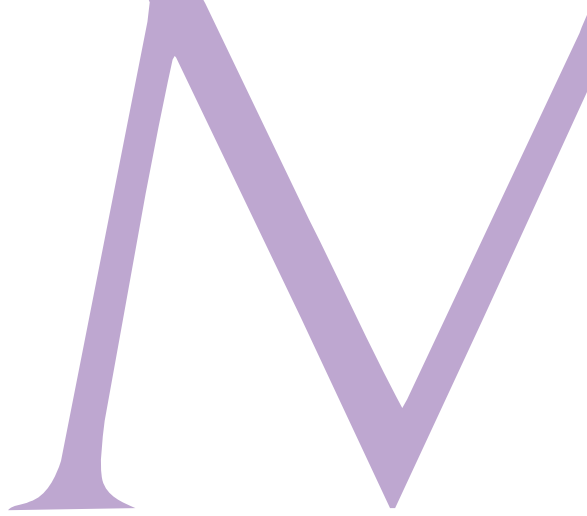

Periódicos científicos

\section{Alunos de graduação também publicam, revisam e editam artigos científicos}

A produção científica brasileira avançou muito na última década, mas permanece o desafio de melhorar seu impacto, medido, entre outras formas, pelo número de citações que um artigo recebe. Além da barreira da escrita fluente em língua estrangeira (sobretudo o inglês), há a da redação científica, a qual poucos cursos de graduação ou pós-graduação contemplam em seus currículos.

Jovens estudantes de várias partes do mundo têm se organizado ao redor de revistas científicas voltadas apenas para a produção acadêmica de graduandos, como espaço para divulgar suas pesquisas, mas sobretudo como estratégia de aprendizado e capacitação de futuros editores, pareceristas e autores.

Em 1997, cinco graduandos de universidades norte-americanas se reuniram motivados a valorizar os trabalhos científicos desenvolvidos por alunos de graduação, que permaneciam "invisíveis", na visão deles. Eles fundaram o Journal of Young Investigators (JYI), para o qual alunos de graduação poderiam enviar seus artigos. Além de escrever artigos, os próprios graduandos, são responsáveis por revisar os manuscritos científicos, editá-los e publicar a versão final. O JYI conta atualmente com cerca de 50 graduandos no mundo inteiro e um corpo de diretores, formado por ex-alunos da graduação, a maioria de instituições dos EUA. "O trabalho voluntário no jornal nos ajuda a trocar ideias e a gerar novas ideias também. Ele expande e facilita a comunicação, mesmo que os alunos estejam separados por muitas milhas", afirma Natalia Norori, de Costa Rica.

Além do JYI, outros periódicos têm perfil semelhante, entre os quais: $B e-$ loit Biologist, Dartmouth Undergraduate Journal of Science, o American Journal of Undergraduate Research e o Journal of Undergraduate Research and Scholarly Excellence. Nestas publicações, os próprios alunos atuam como editores, revisando manuscritos científicos enviados por outros alunos do mundo inteiro. No cargo de editor associado do JYI, por exemplo, o aluno aprende a revisar artigos submetidos através de um treinamento, que dura cerca de seis semanas, sobre o processo que os cientistas chamam de "revisão aos pares", ou peer review, o qual éacompanhado por um aluno mais experiente e pelo orientador, com o qual o aluno em treinamento deve manter reuniōes periódicas. Nessa etapa, as principais seções de um manuscrito científico são trabalhadas: resumo, introdução, materiais e métodos, resultados e discussão, além da revisão de um artigo completo de pesquisa $\mathrm{e}$ uma revisão de literatura. $\mathrm{O}$ treinamento inclui um manual para editor, com detalhes sobre todo o processo de revisão e orientações de como revisar um manuscrito.

O mais importante desse processo é a crítica construtiva que deve ser mantida nas respostas aos autores, já que o objetivo é educativo. Esse é um dos motivos pelo qual a taxa de aprovação de artigos é bastante alta: embora a aprovação seja baixa num primeiro momento, os autores têm a oportunidade de receber todas as orientaçôes dos pareceristas para melhorar o artigo de modo a chegar aos "padróes da ciência". "Há normas adequadas no mundo da publicação científica e nós tentamos ensinar os nossos autores. Se eles decidem aperfeiçoar o manuscrito a partir das nossas edições, eles quase sempre publicam", diz Jai Kumar Mediratta, chefe de desenvolvimento do JYI.

A internacionalização, atualmente muito buscada pelas universidades, também faz parte da vida dos alunos participantes dessas iniciativas, ao entrar em contato com culturas diferentes e pessoas também do meio científico de várias partes do mundo. A equipe e os autores se comunicam 


\section{AJUR}
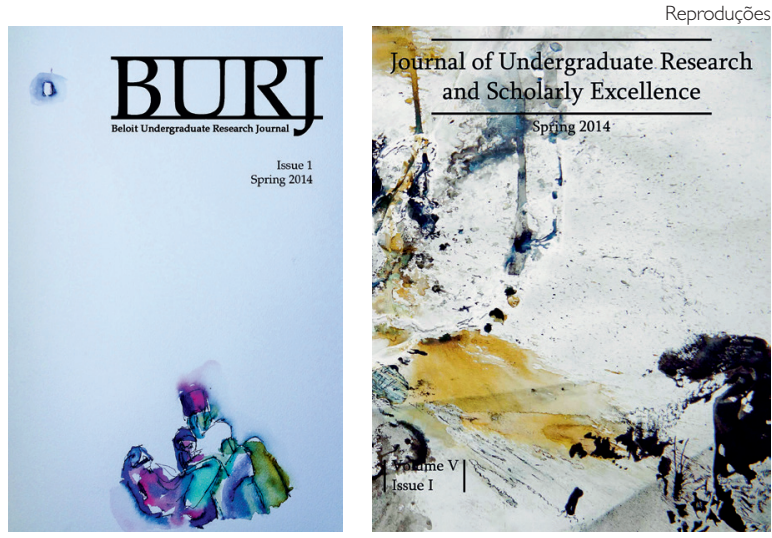

Periódicos científicos internacionais voltados para estudantes de graduação ajudam a familiarizar e capacitar futuros cientistas para a escrita, revisão e edição de artigos

em inglês, por email, ou conversas e reuniôes com uso de ferramentas Skype ou Google hangouts.

No JYI, cerca de $85 \%$ das visualizações da página são provenientes de países de língua inglesa, sendo quase $79 \%$ dos EUA. Atualmente, apenas dois alunos (um brasileiro e uma aluna costa-riquenha) fazem parte da equipe do JYI, como representantes da América Latina. Além de trabalhar com artigos de pesquisa, muitos desses periódicos seguem o padrão de grandes revistas internacionais (como Science e Nature), apresentando também notícias, comentários e possuem apenas a versão online.

CAPACITAÇÃo Experiências da Universidade da Carolina do Sul, nos EUA, mostram que os alunos concordam que há uma melhora na escrita, edição, pesquisa e pensamento crítico através desse processo de revisão aos pares. Embora tenham sido observados casos de plágio ou artigos muito fora dos padrões de ciência (qualidade da ciência, estrutura do manuscrito ou qualidade da escrita) em submissões de fora do país, o que reforça a necessidade de se disseminar a prática da boa conduta desde a graduação.

Para participar dessas publicações, é necessário ter disposição para o trabalho voluntário, que acaba contribuindo para que o estudante se sobressaia nas suas atividades acadêmicas. A ideia é criar uma cultura entre os membros e o envio de boletins online com os "integrantes do mês", brindes para os destaques (como squeezes ou camisetas do jornal) são estratégias usadas para retribuir a colaboração dos estudantes.

Embora não deva se tornar obrigatoriedade aos alunos de graduação, para não causar estresse decorrente

\section{Noticias}

do

Mundo da pressão para publicar que é característica do dia a dia dos pesquisadores "profissionais", essa é uma experiência muito interessante aos alunos que desejam seguir a carreira acadêmica e deverão, obrigatoriamente, escrever artigos para concluírem seus projetos de mestrado e doutorado. Parece ser bastante compensador ter seu próprio artigo publicado quando ainda se é aluno de graduação. Um dos alunos que publicou um artigo no JYI, recentemente postou o comentário " $\mathrm{Ra}$ pazes, finalmente sou um cientista com publicação!".

Além disso, é muito interessante para os graduandos saberem o que outros alunos de graduação andam fazendo. "Estou gostando muito de ver o trabalho de outros alunos de graduação, sejam eles publicados ou não. É fascinante conhecer os interesses desses alunos", revela Kristen Lindeen, editor associado em história no JUR, Universidade do Estado do Colorado (CSU). O único ponto negativo parece ser o final das colaboraçōes. "Minha única tristeza é ter que deixar o trabalho em breve", lamenta Nicole Smith, editor no JUR. $\mathrm{Na}$ página do Council on Undergraduate Research há uma lista com revistas para alunos de graduação: www.cur.org/resources/students/ undergraduate_journals.

Renato Santos 